\title{
The Relationship Between Intimate Partner Violence And Unintended Pregnancy: Analysis of a National Sample From Colombia
}

\begin{abstract}
CONTEXT: Intimate partner violence is associated with a number of reproductive and mental health problems. However, the relationship between intimate partner violence and women's ability to control their fertility has not been adequately explored, especially in developing countries.
\end{abstract}

METHODS: Data from the 2000 Demographic and Health Survey for Colombia were used in multivariate logistic regressions to explore the relationship between intimate partner violence and unintended pregnancy, which was included as a measure of fertility control. Regional differences in the relationship were also explored, and populationattributable risk estimates were calculated. The sample consisted of 3,431 ever-married women aged 15-49 who had given birth in the last five years or were currently pregnant.

RESULTS: Fifty-five percent of respondents had had at least one unintended pregnancy, and 38\% had been physically or sexually abused by their current or most recent partner. Women's adjusted odds of having had an unintended pregnancy were significantly elevated if they had been physically or sexually abused (odds ratio, 1.4); the association was observed in the Atlántica and Central regions (1.7 each), but was not significant elsewhere in the country. Eliminating intimate partner violence in Colombia would result in an estimated 32,523-44,986 fewer unintended pregnancies each year.

CONCLUSIONS: These findings indicate the need to include intimate partner violence screening and treatment in reproductive health programs, to promote men's involvement in fertility control programs, and to improve the social and political response to intimate partner violence.

International Family Planning Perspectives, 2004, 30(4):165-173

The infliction of violence by intimate partners is common in many societies and affects millions of women throughout the world each year. Partner abuse's private nature has made it difficult to quantify its prevalence, understand its risk factors or address its consequences. In the last decade, however, research has revealed high rates of intimate partner violence in the United States and worldwide, ${ }^{1}$ and has identified some of the direct and indirect health consequences of abuse, including mental and reproductive health problems. ${ }^{2}$ Studies have also reported high rates of abuse during pregnancy ${ }^{3}$ and have linked such abuse to intrauterine growth restriction, low birth weight, fetal and infant death and other maternal complications. ${ }^{4}$

However, the relationship between intimate partner violence and women's ability to control their fertility has not been adequately explored, especially among women in developing countries. ${ }^{5}$ One indicator of a lack of fertility control is unintended (i.e., mistimed or unwanted) pregnancy, which has been associated with adverse outcomes for women, fetuses and infants. ${ }^{6}$ Therefore, it is important to understand the risk factors for unintended pregnancy, particularly those related to intimate partner violence.

Some of the existing research on intimate partner violence and fertility control has focused on women's fear of violence as a barrier to contraceptive use in general. ${ }^{7}$ Other researchers have explored relationships between partner abuse and the use of male methods, because women may face violence when attempting to negotiate condom use, ${ }^{8}$ and between abuse and female methods, because partners may become abusive when they discover covert use or suspect infidelity. ${ }^{9}$ While the anecdotal evidence from these studies helps clarify the mechanisms through which violence and fear of violence could affect fertility control, the issue merits further investigation.

With the exception of a few studies based on data from postpartum women in the United States, limited quantitative research has directly explored the relationship between intimate partner violence and fertility control. ${ }^{10}$ Several studies found that women who had experienced intimate partner violence during pregnancy were more likely than nonabused women to report that the pregnancy was unplanned or closely spaced, or that they had had unhappy feelings about it. ${ }^{11}$ However, these studies examined bivariate relationships without controlling for other factors. Another study found no significant association between abuse and unwanted pregnancy, but the fact that mistimed pregnancies were categorized with wanted pregnancies may have affected the findings. ${ }^{12}$

Most induced abortions are of pregnancies that were unintended. Studies exploring intimate partner violence
By Christina C. Pallitto and Patricia O'Campo

Christina Pallitto is an independent consultant, San Salvador, El Salvador. Patricia O'Campo is director, Inner City Health Research Unit, and professor of public health sciences, University of Toronto, Toronto, Canada. At the time this article was written the authors were, respectively, doctoral candidate and professor, Department of Population and Health Sciences, Johns Hopkins Bloomberg School of Public Health, Baltimore, MD, USA. 
TABLE 1. Selected characteristics of ever-married women who had given birth in the last five years or were currently pregnant, and of ever-married women who had not given birth during that time and were not currently pregnant, Colombia Demographic and Health Survey, 2000

Characteristic

Recent birth No recent or current birth or pregnancy current $(\mathrm{N}=3,431) \quad$ pregnancy $(\mathrm{N}=4,285)$

Demographic

Age at first birth (mean yrs.)

No. of children (mean)

Socioeconomic composite score (mean)

Have item in household (\%)

Refrigerator

Telephone

Radio

Television

Running water

Durable floor

Flush toilet

Urban residence (\%)

Education level (\%)

None

Primary

Secondary

Higher than secondary

Employment (\%)

Professional, technical or managerial

Clerical or sales

Manual, agricultural or service

None

Currently married or living

with partner (\%)

Region

Atlántica

Bogotá

Central

Oriental

Pacífica

Fertility

Ever used contraceptives (\%)

Currently using contraceptives (\%)

Big problem if became pregnant (\%)‡

Ever had a terminated pregnancy (\%)

Discussed family planning

with partner (\%)

Discussed family planning

with nonpartner (\%)

Abuse

Father hit mother (\%)

Ever forced to have sex

by nonpartner (\%)

*Difference from women with no recent birth or current pregnancy significant at $\mathrm{p}<.05$. ${ }^{* *}$ Difference from women with no recent birth or current pregnancy significant at $\mathrm{p}<.01{ }^{* * *}$ Difference from women with no recent birth or current pregnancy significant at $p<.001$. †The sample for this measure was limited to women who had ever given birth. Percentages are based on 3,297 women with a recent birth or current pregnancy and 3,878 women with no recent birth or current pregnancy. $¥$ Based on 2,311 women with a recent birth or current preg-

nancy and 2,029 with no recent birth or current pregnancy.

among women obtaining abortions therefore provide important information about the association between intimate partner violence and unintended pregnancy. ${ }^{13}$ One such study revealed a significant association between abuse and abortion. ${ }^{14}$ Three others found that rates of prior abortion were significantly higher among abused women than among nonabused women. ${ }^{15}$
These studies provide some evidence that a relationship exists between partner abuse and unintended pregnancy. However, more investigation is needed to determine whether the relationship would be significant in a multivariate analysis and whether similar results would be found in other contexts, particularly in developing countries. In this study, we used multivariate logistic regressions to explore the relationship between intimate partner violence and unintended pregnancy in a population-based sample of Colombian women. It is the first study to explore this issue in a Latin American setting.

\section{METHODS}

\section{Data}

Analyses are based on cross-sectional data from the 2000 Demographic and Health Survey (DHS) for Colombia. ${ }^{16}$ We used information from the women's questionnaire, in which women of reproductive age (15-49) were asked about their reproductive and sexual history, contraceptive knowledge and practices, knowledge and attitudes about HIV/AIDS, fertility desires, nutritional status, family violence experience and births in the last five years. Of the 11,585 women surveyed, 7,716 had ever been married (i.e., legally married or in a cohabiting relationship) and answered a series of questions related to intimate partner violence; lack of privacy prevented interviewers from asking these questions of an additional 31 ever-married respondents. The remaining 3,838 women had never been married and thus could not have experienced abuse by an intimate partner (which is defined in this study as a legal spouse or cohabiting partner).

Of the 7,716 respondents who completed the partner violence module, 3,431 reported that they had given birth in the last five years or were currently pregnant, and therefore could have had an unintended pregnancy. * This subgroup, which we refer to as "recently pregnant women," makes up the sample for our analysis.

\section{Abuse Variables}

A woman was categorized as having experienced physical abuse if she answered affirmatively when asked if her partner had pushed her, hit her with his hand, hit her with a hard object, bitten her, kicked or dragged her, threatened her with a knife or gun, attacked her with a knife or gun, or tried to choke or burn her, either sometimes or frequently. A woman was classified as having experienced sexual abuse if she stated that her partner had forced her to have sex, either sometimes or frequently. We pooled this information to create an aggregate measure of abuse, which was coded positive for all women who reported either physical or sexual violence at any frequency.

It should be noted that respondents were asked about their experience of abuse in their current or most recent partnership, rather than over their lifetime. As a result, we assume that this analysis underestimates actual rates of

*Women in the study population had 4,684 pregnancies in 1995-2000, of which approximately one-half were unintended. Of the unintended pregnancies, $54 \%$ were mistimed and $46 \%$ were unwanted. 
abuse and indicates a weaker relationship between abuse and unintended pregnancy than actually exists. In addition, because respondents were not asked when abuse occurred relative to each unintended pregnancy, they could have been abused by a partner other than one with whom they had an unintended pregnancy.

\section{Unintended Pregnancy Variable}

Respondents were asked about the intendedness of all pregnancies they had had in the last five years that had ended in live births, and about the intendedness of their current pregnancy (if relevant). For each pregnancy, women were asked whether they had wanted the pregnancy at the time of conception, had wanted it later or had not wanted it at all. We categorized women as having had an unintended pregnancy if they reported their current or any past pregnancy as wanted later or not at all. We chose to make this variable dichotomous rather than continuous because 79\% of the 1,900 women who reported at least one unintended pregnancy reported only one.

\section{Explanatory Variables}

Demographic variables included women's age, number of children, urban or rural residence and education level (none, primary, secondary or higher than secondary). To measure socioeconomic status, we created a composite score that summarized how many of the following items were in respondents' households: refrigerator, telephone, radio, television, running water, durable flooring materials and flush toilet.

Fertility-related characteristics included whether women had ever had a pregnancy that terminated early (without distinguishing between spontaneous and induced abortion); whether they had had a child who died; whether they had ever used modern contraceptives; whether they were currently using modern contraceptives; and whether they had discussed family planning with their partner or with someone other than their partner. Other abuse-related variables included whether women had a family history of abuse (i.e., whether their father hit their mother) and whether someone other than their partner ever forced them to have sex.

\section{Analysis}

All analyses were conducted using Stata statistical analysis software. We calculated descriptive statistics for demographic and fertility-related characteristics, family abuse history and coerced sex by a nonpartner among the 3,431 ever-married women who had given birth in the last five years or were currently pregnant, and among the 4,285 evermarried women who did not report a recent birth or current pregnancy. We compared the two groups using t-tests for continuous variables and chi-square tests for categorical variables to determine how representative recently pregnant women were of all ever-married respondents.

We summarized rates of intimate partner violence among recently pregnant women for each type of abuse and determined the overlap of physical and sexual violence. We decided to categorize women who reported either type of

\begin{tabular}{|c|c|c|c|}
\hline Type and act of abuse & Frequently & Sometimes & Total \\
\hline \multicolumn{4}{|l|}{ Physical } \\
\hline Pushed & 4.2 & 29.1 & 33.2 \\
\hline Hit with hand & 3.3 & 23.4 & 26.7 \\
\hline Hit with hard object & 1.7 & 4.9 & 6.6 \\
\hline Bit & 0.5 & 2.8 & 3.3 \\
\hline Kicked or dragged & 1.6 & 8.7 & 12.4 \\
\hline Threatened with knife or gun & 0.7 & 5.5 & 6.3 \\
\hline Attacked with knife or gun & 0.3 & 2.3 & 2.6 \\
\hline Tried to choke or burn & 0.4 & 3.2 & 3.7 \\
\hline Sexual & 1.5 & 7.1 & 8.5 \\
\hline
\end{tabular}

violence in one group, although it could be argued that the mechanisms that operate between physical abuse and fertility control are different from those that operate between sexual abuse and fertility control. However, most women who reported any type of violence had not been sexually abused (77\%), and the number of recently pregnant women who had experienced sexual abuse without physical violence was too small for meaningful analysis. We included the 293 women (9\%) who had experienced sexual abuse alone or in combination with nonsexual physical violence, because sexual abuse is a form of physical abuse and is likely to affect women's fertility control.

Verbal abuse was not considered as a separate category because the majority of verbally abused women had also been physically or sexually abused. The 218 women who reported verbal abuse without any other form of abuse did not constitute an analytically viable group.

We conducted bivariate logistic regression analyses to calculate the unadjusted odds of unintended pregnancy associated with the summary measure of physical and sexual abuse and with respondents' demographic and fertility-related characteristics. We used these findings to construct a series of multiple logistic regression models, each of which included unintended pregnancy as the dependent variable and physical or sexual abuse as the main independent variable. All models controlled for age, education level, number of children, socioeconomic composite score and urban or rural residence. We then added the following variables and assessed their significance: ever-use of contraceptives, current contraceptive use, family abuse history, coerced sex by a nonpartner, a pregnancy that had terminated early, a child who had died, and discussion of family planning with a partner and with a nonpartner.

We tested for interactions between abuse and age, education level, urban residence and socioeconomic status, and between socioeconomic status and urban residence. We assessed the significance of the interaction terms and conducted likelihood ratio tests to determine whether the model fit improved when interaction terms were added.

\section{Regional Variation}

To determine whether relationships between intimate partner violence and unintended pregnancy were similar across the country, we compared rates of abuse and unintended 


\begin{tabular}{|c|c|}
\hline Characteristic & Odds ratio \\
\hline \multicolumn{2}{|l|}{ Demographic } \\
\hline Age & 0.99 \\
\hline Age at first birth & $0.93 * * *$ \\
\hline No. of children & $1.46^{* * *}$ \\
\hline Socioeconomic composite score & $0.91^{* * *}$ \\
\hline Urban residence & 0.93 \\
\hline \multicolumn{2}{|l|}{ Fertility } \\
\hline Ever used contraceptives & 1.05 \\
\hline Currently using contraceptives & $0.86^{*}$ \\
\hline Big problem if became pregnant $†$ & $2.13^{* * *}$ \\
\hline Ever had a terminated pregnancy & 0.87 \\
\hline Discussed family planning with partner & 0.90 \\
\hline Discussed family planning with nonpartner & 0.94 \\
\hline \multicolumn{2}{|l|}{ Abuse } \\
\hline Physical or sexual abuse by partner & $1.64^{* * *}$ \\
\hline Father hit mother & $1.05^{*}$ \\
\hline Ever forced to have sex by nonpartner & $1.48^{* *}$ \\
\hline
\end{tabular}

pregnancy-and associations between the two-across five main regions: Atlántica, Bogotá, Central, Oriental and Pacífica. An in-depth analysis of municipality-level differences was presented elsewhere. ${ }^{17}$ Although we controlled for socioeconomic status and urban or rural residence, the great diversity and complexity of Colombian society are not fully captured in our analysis of the national sample.

\section{Population-Attributable Risk}

We calculated the population-level risk of unintended pregnancy in Colombia that could be attributed to intimate partner violence (i.e., population-attributable risk), after adjusting for confounding factors, to estimate the reduction in unintended pregnancy that would result if intimate partner violence could be eliminated. We then used rates of birth, induced abortion and unintended pregnancy to calculate the total number of unintended births and abortions of unintended pregnancies that could be avoided by eliminating intimate partner violence in Colombia.

\section{RESULTS}

As shown in Table 1 (page 166), respondents who had given birth in the last five years or were currently pregnant had a mean age of 28, a mean age at first birth of 21 , a mean of 2.3 children and a mean socioeconomic composite score of 4.9. Although most of these women had a radio, television, running water and durable floor (81-84\%), lower proportions had a refrigerator, telephone and flush toilet (40-63\%). The majority lived in urban areas (69\%). Almost half $(48 \%)$ had a secondary education, but only $9 \%$ had been educated at a higher level.

Most recently pregnant respondents said they had ever used modern contraceptives (88\%), and 55\% were using a modern method at the time of the survey. One-half stated that becoming pregnant now would be a big problem.
Nearly one-quarter said they had had a pregnancy that terminated early. While only 17\% reported discussing family planning with their partner, $52 \%$ had discussed family planning with someone other than their partner. Further investigation revealed that $84 \%$ of women who were not using contraceptives and said that becoming pregnant would be a big problem were either breast-feeding, unmarried, not having sex, menopausal or subfecund (not shown)

Recently pregnant women differed significantly from other respondents on most of these measures: mean age, number of children and socioeconomic composite score; and each of the household items, urban residence, education level, employment, marital status, all fertility-related characteristics and family history of intimate partner violence.

Thirty-eight percent of recently pregnant women had experienced physical or sexual violence, $29 \%$ reported physical abuse only, $1 \%$ reported sexual abuse only and $7 \%$ had experienced both types of violence. The most common forms of physical abuse reported (Table 2, page 167) were being pushed by a partner (33\%) and being hit with a hand (27\%); the least common were being bitten and being attacked with a knife or gun (3\% each). The majority of women reporting any act of abuse said that the abuse occurred only sometimes. Approximately $18 \%$ of the women reported severe consequences of abuse, including pain, wounds, broken bones, pregnancy loss, organ damage or loss of bodily function (not shown).

Slightly more than half of the women (55\%) had had at least one unintended pregnancy in 1995-2000. Among women who had experienced physical or sexual abuse, the proportion who reported at least one recent birth or current pregnancy as unintended was higher than the proportion who reported all recent births and current pregnancies as wanted (63\% v. 37\%). Among nonabused women, however, there was basically no difference between these two proportions ( $51 \%$ v. $49 \%$ ).

Table 3 shows unadjusted odds ratios for unintended pregnancy and respondents' demographic and fertility-related characteristics, and abuse-related variables. Women's odds

TABLE 4. Among ever-married women who had given birth in the last five years or were currently pregnant, odds ratios from multivariate logistic regression assessing the association of abuse and other characteristics with unintended pregnancy

\begin{tabular}{ll} 
Characteristic & Odds ratio \\
\hline Physical or sexual abuse & $1.41^{* * *}$ \\
Age† & $0.92^{* * *}$ \\
Education level & 1.09 \\
Primary & 1.29 \\
Secondary & 1.47 \\
Higher than secondary & $1.88^{* * *}$ \\
No. of children¥ & $1.07^{*}$ \\
Socioeconomic composite score & $0.81^{*}$ \\
Ever had a terminated pregnancy & $0.90^{*}$
\end{tabular}

${ }^{*} \mathrm{p}<.05 .{ }^{* * *} \mathrm{p}<.001$. Odds ratio indicates change in risk of unintended pregnancy with each year of age above the average of 28 . $\neq$ Odds ratio indicates change in risk of unintended pregnancy with each additional child above the average of two. 
TABLE 5. Among ever-married women who had given birth in the last five years or were currently pregnant, percentage who reported physical or sexual abuse, percentage who reported at least one unintended pregnancy, and adjusted odds ratios, by region

\begin{tabular}{llll} 
Region & $\begin{array}{l}\text { Physical or } \\
\text { sexual abuse }\end{array}$ & $\begin{array}{l}\text { Unintended } \\
\text { pregnancy }\end{array}$ & $\begin{array}{l}\text { Odds } \\
\text { ratio }\end{array}$ \\
\hline Atlántica & 31.1 & 53.7 & $1.65^{* *}$ \\
Bogotá & 42.1 & 53.9 & 1.22 \\
Central & 35.7 & 55.9 & $1.66^{* *}$ \\
Oriental & 41.3 & 56.4 & 1.13 \\
Pacífica & 45.4 & 58.0 & 1.15 \\
\hline
\end{tabular}

${ }^{* *} \mathrm{p}<.01$. Notes: Figures based on 1,002 women for Atlántica; 468 women for Bogotá; 861 women for Central; 571 women for Oriental; and 529 women for Pacífica. Odds ratios are adjusted for age, number of children, socioeconomic composite score, education level, history of terminated pregnancy and interaction between socioeconomic composite score and urban residence; the odds ratio for Bogotá was not adjusted for the interaction between socioeconomic score and urban residence because that region is considered urban.

of having had an unintended pregnancy decreased significantly as age at first birth and socioeconomic composite score increased (odds ratio, 0.9 for both measures); the odds increased with each additional child (1.5). As expected, current contraceptive use was a protective factor against unintended pregnancy (0.9), and women who stated that it would be a big problem if they became pregnant had an increased likelihood of having an unintended pregnancy (2.1). Having a parental history of intimate partner violence and coerced sex by a nonpartner were positively associated with unintended pregnancy (1.1 and 1.5, respectively). We also found a statistically significant relationship between unintended pregnancy and intimate partner violence (1.6).

In a logistic regression analysis that controlled for demographic and fertility-related factors (Table 4), ${ }^{*}$ intimate partner violence was significantly associated with unintended pregnancy after we controlled for other factors (odds ratio, 1.4). Each additional year above the average age of 28 was significantly associated with a reduction in women's risk of unintended pregnancy (0.9). Each additional child above the average of two children was associated with an elevated risk of unintended pregnancy (1.9). ${ }^{\dagger}$ The odds also increased significantly with each additional point on the respondents' socioeconomic composite score (1.1). Women who had had a pregnancy that terminated early were significantly less likely to report an unintended pregnancy than were women without this characteristic (0.8). Education level was not significantly associated with women's risk of unintended pregnancy in this model.

We found a statistically significant interaction between socioeconomic composite score and urban residence, which suggests that socioeconomic status was an important protective factor against unintended pregnancy only in urban areas. Although we tested other interaction terms, this was the only one that was statistically significant or improved the model fit.

Table 5 shows percentages of women experiencing intimate partner violence and unintended pregnancy, as well as adjusted odds ratios, in the five major geographic regions. The rate of abuse was highest in the Pacífica region (45\%), followed by Bogotá (42\%) and Oriental (41\%). The Atlántica region had the lowest rate of abuse (31\%) and, along with Bogotá, had the lowest rate of unintended pregnancy (54\%), while the Pacífica region had the highest rate of unintended pregnancy (58\%). Adjusted odds ratios indicated that unintended pregnancy was significantly more common among abused women than among other women in both the Atlántica and the Central region (odds ratios, 1.7 for both regions).

Calculations based on population-attributable risk estimates suggest that unintended pregnancies would decrease by $5 \%$ if intimate partner violence were eliminated in Colombia. This would translate to 24,736 fewer unintended births ${ }^{\ddagger}$ and 7,787-20,250 fewer abortions per year, § for a total of 32,523-44,986 fewer unintended pregnancies annually.

\section{DISCUSSION}

We found a moderate relationship between unintended pregnancy and intimate partner violence, even after we adjusted for respondents' demographic and fertility-related characteristics. This relationship may be explained by several different mechanisms. One possibility is that some women became pregnant unintentionally as a direct result of sexual abuse. However, because women who reported only physical abuse also had an elevated risk of unintended pregnancy, it is more likely that another mechanism was at work, in which abused women living in an environment of fear and male dominance lacked the ability to control their fertility.

In a previous study based on the same Colombian data, Pallitto and O'Campo tested the community-level effects of gender inequality, female autonomy and patriarchal control on the relationship between intimate partner violence and fertility control. ${ }^{18}$ Having had an unintended pregnancy was significantly associated with living in a highly patriarchal community and living in a community with a high rate of intimate partner violence. Although previous studies have

*Contraceptive use, family abuse history, coerced sex by a nonpartner, and discussion of family planning with a partner and with a nonpartner did not have significant effects and were omitted from the model.

†Age and number of children were centered around average values to make the results more interpretable.

‡Colombia's birthrate is approximately 21.6 births per 1,000 people, and the population in January 2003 was approximately $41,662,073$ people (source: Central Intelligence Agency, The World Factbook 2003, 2003, $<$ http://www.cia.gov/cia/publications/factbook/geos/co.html>, accessed Jan. 10, 2004). Using these statistics, we calculated the total number of births per year to be 899,484 and-given that $55 \%$ of births reported in the 2000 Demographic and Health Survey for Colombia were unintended-the tota number of unintended births per year to be 494,716 . If unintended pregnancies could be reduced by $5 \%$ by eliminating intimate partner violence, then 24,736 unintended births could be avoided each year.

$\S$ This figure is based on a range of abortion estimates for Colombia; the most conservative estimate is 173,037 abortions per year (source: Singh S and Wulf D, 1994, reference 30), and the highest estimate is 450,000 abortions per year (source: reference 29 ). We assumed that $90 \%$ of abortions $(155,733-405,000)$ are due to unintended pregnancy, because a study of U.S. women showed that $10 \%$ of abortions were obtained for other reasons (source: reference 31 ). A $5 \%$ reduction in abortions would result in 7,787-20,250 fewer abortions per year and 32,523-44,986 fewer unintended pregnancies (births plus abortions) per year. This probably underestimates the total number of unintended pregnancies that could be avoided, because at least some unintended pregnancies end in spontaneous abortion, which presumably would also be reduced if intimate partner violence were eliminated. 
provided some evidence that gender inequality is associated with intimate partner violence, ${ }^{19}$ and that a lack of autonomy or status is linked to a lack of fertility control, ${ }^{20}$ the Colombian study was the first to explore the effects of these constructs on the relationship between intimate partner violence and unintended pregnancy.

The community-level study provides an in-depth analysis of the regional variations in intimate partner violence and unintended pregnancy that were presented here. The presence of regional variations indicates the heterogeneity of Colombian society and the need to consider cultural and regional differences that were not controlled for in this analysis. Further investigation is warranted to determine which subregions or municipalities have particularly high rates of intimate partner violence and unintended pregnancy, to explore the risk factors that exist in these areas and to target resources and programs to address these problems.

A few limitations of the study must be noted. Variables related to partner beliefs and characteristics were not included in the multivariate regression models because a large amount of partner data was missing. As a result, it was impossible to determine the effects of these variables on women's pregnancy intentions and fertility control. However, previous research has suggested that societies in which women's status is improving may exhibit higher rates of intimate partner violence than those in which gender roles are static. ${ }^{21}$ In the Colombian data, high rates of intimate partner violence and unintended pregnancy, and the association between the two, suggest a tension between women and their partners. Further investigation is warranted to determine how these phenomena are associated with changes in women's status and gender relations at the societal level.

The potential for underreporting is an important concern in research on intimate partner violence because of the sensitivity of the subject, social stigma and participants' privacy and safety concerns. Women may not respond honestly to sensitive questions and may be at risk for further abuse or psychological trauma if the researchers do not adequately address safety and ethical issues. ${ }^{22}$ The problem of underreporting has been demonstrated by Ellsberg and colleagues, who showed that two studies specifically designed to capture data on intimate partner violence among Nicaraguan women yielded higher rates than analyses of data collected in the intimate partner violence module of the DHS. ${ }^{23}$ Rates of lifetime abuse were $52 \%$ in a study conducted in León and 69\% in a study in Managua, compared with only $28 \%$ in the nationally representative DHS.

Although it is possible that rates of intimate partner violence were higher in León and Managua than in the rest of the country, Ellsberg and colleagues suggested that results from the studies that focused on partner abuse were more accurate than those based on DHS data because interviewers were trained specifically to collect violence data, safety and security concerns were more fully addressed and referral services were offered. In light of these findings and the fact that the Colombian DHS did not measure lifetime abuse, it is likely that rates of violence found in our study are underestimates, and that the association between intimate partner violence and unintended pregnancy was weakened.

The cross-sectional nature of the Colombian DHS limits the conclusions that can be drawn from this analysis in several ways. First, there is potential for recall bias or instability in reports of pregnancy intendedness for the preceding five years. Previous studies have shown that women's perceptions of wantedness might change over time and, specifically, that a pregnancy that was originally considered unwanted could be categorized as wanted after the birth. ${ }^{24}$ In addition, it is not possible to assess the chronology of the relationship between intimate partner violence and unintended pregnancy from these data, although the fact that five years' worth of pregnancy data are analyzed makes the estimates more reliable.

We hypothesized that violence leads to unintended pregnancy, but it could also be argued that unintended pregnancy precipitates abuse. Our hypothesis is supported by several studies in which the majority of women who had been physically or sexually abused during pregnancy reported that the abuse had begun before they got pregnant. ${ }^{25}$ A study by Saltzman and colleagues also revealed lower rates of abuse during pregnancy than before pregnancy, ${ }^{26}$ a finding that is supported by a study from Mexico, which showed that physical and sexual abuse decreased during pregnancy despite increases in emotional abuse. ${ }^{27}$ In another study, Ellsberg and colleagues established the early onset of abuse among married women in a large sample from Nicaragua, which provides further evidence of abuse preceding pregnancy. ${ }^{28}$

Our study is also limited by the unavailability of intendedness data for pregnancies that occurred more than five years before the survey. The sample of women who had been pregnant in the last five years was not representative of all ever-married respondents; further analysis revealed that rates of physical and sexual abuse were significantly elevated, and rates of current partnership were significantly reduced, among ever-married women who did not report a recent birth or current pregnancy. Excluding these respondents from the analysis may have caused us to underestimate the association between intimate partner violence and unintended pregnancy.

Intendedness was measured only for pregnancies that ended in live births; our analysis could not account for pregnancies that terminated early because of spontaneous or induced abortion. Although induced abortion is illegal in Colombia, one study estimated that 450,000 abortions occur in the country each year; ${ }^{29}$ more conservative estimates range from 173,037 to $404,000 .{ }^{30}$ Because pregnancies that end in abortion are generally unintended, ${ }^{31}$ the lack of intendedness data on terminated pregnancies probably caused us to underestimate rates of unintended pregnancy. This assumption is supported by our finding that women's odds of having had an unintended pregnancy that ended in a live birth were significantly reduced if they had had a pregnancy that terminated early.

Despite these limitations, the findings presented here 
reveal a significant relationship between intimate partner violence and unintended pregnancy. This is the first population-based study from a Latin American country to find such an association. Further exploration of the mechanisms that govern the relationship between intimate partner violence and unintended pregnancy is warranted, and more research is needed to address similar questions in other Latin American countries and in other regions of the world. In addition, qualitative research would help broaden our understanding of the link between intimate partner violence and unintended pregnancy and of how that relationship is influenced by gender relations at the community and societal levels.

Unintended pregnancy is associated with many adverse health outcomes for women and infants, including late entry into prenatal care, low birth weight, very low birth weight, perinatal mortality and postpartum complications. ${ }^{32}$ In addition, unintended births are less likely than planned births to occur in an institutional setting, and infants whose conception was unintended are less likely to be breast-fed. ${ }^{33}$ Other adverse outcomes may include maternal mortality from abortion complications, especially in countries where abortion is illegal. ${ }^{34}$ Our findings based on populationattributable risk suggest that the enormous public health implications of unintended pregnancy could be substantially reduced by decreasing or eliminating intimate partner violence. In this context, efforts to reduce risk factors for unintended pregnancy, including intimate partner violence, deserve increased support.

\section{CONCLUSION}

The dynamic nature of Colombian society, the rapid changes that have occurred in women's education and employment, and changes in fertility rates over the last 30 years make Colombia an important setting in which to address intimate partner violence and fertility control. Colombian law provides a legal basis for protecting women from abuse; however, the enforcement and application of the law are inconsistent. $^{35}$ While many governmental and nongovernmental organizations in Colombia work toward preventing and addressing intimate partner violence, additional efforts are needed to promote reproductive health programs that involve men; screen women for intimate partner violence in health care settings; undertake campaigns at the societal level to break the intergenerational cycle of considering abuse a socially acceptable behavior; provide protective services for abused women, such as shelters and support groups; and improve women's status through educational and occupational advances.

By gaining a greater understanding of the relationship between partner abuse and fertility control in Colombia, local and international efforts can more effectively address women's risk of violence and unintended pregnancy and the resultant threats to women's health, safety and wellbeing. This study demonstrates the magnitude of these social problems and the urgency with which they must be addressed.

\section{REFERENCES}

1. Heise L, Ellsberg M and Gottemoeller M, Ending violence against women, Population Reports, 1999, Series L, No. 11; and Ellsberg MC et al., Wife abuse among women of childbearing age in Nicaragua, American Journal of Public Health, 1999, 89(2):241-244.

2. Campbell J et al., Intimate partner violence and physical health consequences, Archives of Internal Medicine, 2002, 162(10):1157-1163; Golding JM, Intimate partner violence as a risk factor for mental disorders: a meta-analysis, Journal of Family Violence, 1999, 14(2):99-132; Moore M, Reproductive health and intimate partner violence, Family Planning Perspectives, 1999, 31(6):302-306 \& 312; Heise L, Ellsberg M and Gottemoeller M, 1999, op. cit. (see reference 1); and Ellsberg M, Domestic violence and emotional distress among Nicaraguan women: results from a population-based study, American Psychologist, 1999, 54(1):30-36.

3. Cokkinides VE and Coker AL, Experiencing physical violence during pregnancy: prevalence and correlates, Family and Community Health, 1998, 20(4):19-37; Gazmararian JA et al., Prevalence of violence against pregnant women, Journal of the American Medical Association, 1996, 275(24):1915-1920; Johnson JK et al., The prevalence of domestic violence in pregnant women, BJOG: An International Journal of Obstetrics and Gynaecology, 2003, 110(3):272-275; and Valladares E et al., Physical partner abuse during pregnancy: a risk factor for low birth weight in Nicaragua, Obstetrics \& Gynecology, 2002, 100(4):700-705.

4. Bullock LF and McFarlane J, The birth-weight/battering connection, American Journal of Nursing, 1989, 89(9):1153-1155; Murphy CC et al., Abuse: a risk factor for low birth weight? a systematic review and meta-analysis, Canadian Medical Association Journal, 2001, 164(11):15671572; Parker B, McFarlane J and Soeken K, Abuse during pregnancy: effects on maternal complications and birth weight in adult and teenage women, Obstetrics \& Gynecology, 1994, 84(3):323-328; Petersen R et al., Violence and adverse pregnancy outcomes: a review of the literature and directions for future research, American Journal of Preventive Medicine, 1997, 13(5):366-373; Valladares E et al., 2002, op. cit. (see reference 3); Janssen PA et al., Intimate partner violence and adverse pregnancy outcomes: a population-based study, American Journal of Obstetrics and Gynecology, 2003, 188(5):1341-1347; Jejeebhoy SJ, Associations between wife-beating and fetal and infant death: impressions from a survey in rural India, Studies in Family Planning, 1998, 29(3): 300-308; and Cokkinides VE et al., Physical violence during pregnancy: maternal complications and birth outcomes, Obstetrics \& Gynecology, 1999, 93(5):661-666

5. Heise L, Violence, sexuality and women's lives, in: Parker RG and Gagnon JH, eds., Conceiving Sexuality: Approaches to Sex Research in a Postmodern World, New York: Routledge, 1995; Dixon-Mueller R, The sexuality connection in reproductive health, Studies in Family Planning, 1993, 24(5):269-282; and Folch-Lyon E, de la Macorra L and Schearer SB, Focus group and survey research on family planning in Mexico, Studies in Family Planning, 1981, 12(12):409-432.

6. Bustan MN and Coker AL, Maternal attitude toward pregnancy and the risk of neonatal death, American Journal of Public Health, 1994, 84(3):411-414; Conde-Agudelo A and Belizán JM, Maternal morbidity and mortality associated with interpregnancy interval: cross sectional study, BMJ, 2000, 321(7271):1255-1259; Konje JC, Obisesan KA and Ladipo OA, Health and economic consequences of septic induced abortion, International Journal of Gynaecology and Obstetrics, 1992, 37(3): 193-197; Marsiglio W and Mott FL, Does wanting to become pregnant with a first child affect subsequent maternal behaviors and infant birth weight? Journal of Marriage and Family, 1988, 50(4):1023-1036; and Sable MR et al., Pregnancy wantedness and adverse pregnancy outcomes: differences by race and Medicaid status, Family Planning Perspectives, 1997, 29(2):76-81.

7. Heise L, 1995, op. cit. (see reference 5); and Bawah AA et al., Women's fears and men's anxieties: the impact of family planning on gender relations in northern Ghana, Studies in Family Planning, 1999, 30(1):54-66.

8. Eby KK, Campbell JC and Sullivan CM, Health effects of experiences of sexual violence for women with abusive partners, Health Care for Women International, 1995, 16(6):563-576.

9. Bawah AA et al., 1999, op. cit. (see reference 7); Biddlecom AE and Fapohunda BM, Covert contraceptive use: prevalence, motivations, and consequences, Studies in Family Planning, 1998, 29(4):360372; Fapohunda BM, Covert contraceptive use: prevalence, motivations, 
and consequences, Studies in Family Planning, 1998, 29(4):360-372; and Rao V, Wife beating in rural south India: a qualitative and econometric analysis, Social Science \& Medicine, 1997, 44(8):1169-1180.

10. Goodwin MM et al., Pregnancy intendedness and physical abuse around the time of pregnancy: findings from the pregnancy risk assessment monitoring system, 1996-1997, Maternal and Child Health Journal, 2000, 4(2):85-92; and Gazmararian JA et al., The relationship between pregnancy intendedness and physical violence in mothers of newborns, Obstetrics \& Gynecology, 1995, 85(6):1031-1038.

11. Hillard PJA, Physical abuse in pregnancy, Obstetrics \& Gynecology, 1985, 66(2):185-190; Stewart DE and Cecutti A, Physical abuse in pregnancy, Canadian Medical Association Journal, 1993, 149(9):1257-1263; Jacoby $\mathrm{M}$ et al., Rapid repeat pregnancy and experiences of interpersonal violence among low-income adolescents, American Journal of Preventive Medicine, 1999, 16(4):318-321; and Amaro H et al., Violence during pregnancy and substance use, American Journal of Public Health, 1990, 80(5):575-579.

12. Cokkinides VE and Coker AL, 1998, op. cit. (see reference 3).

13. Evins $G$ and Chescheir N, Prevalence of domestic violence among women seeking abortion services, Women's Health Issues, 1996, 6(4):204210; Glander SS et al., The prevalence of domestic violence among women seeking abortion, Obstetrics \& Gynecology, 1998, 91(6):10021006; and Leung TW et al., A comparison of the prevalence of domestic violence between patients seeking termination of pregnancy and other general gynecology patients, International Journal of Gynaecology and Obstetrics, 2002, 77(1):47-54

14. Leung TW et al., 2002, op. cit. (see reference 13).

15. Amaro H et al., 1990, op. cit. (see reference 11); Janssen PA et al., 2003, op. cit. (see reference 4); and Webster J, Chandler J and Battistutta D, Pregnancy outcomes and health care use: effects of abuse, American Journal of Obstetrics and Gynecology, 1996, 174(2):760-767.

16. Ojeda G, Ordoñez M and Ochoa LH, Salud Sexual y Reproductiva en Colombia: Encuesta Nacional de Demografía y Salud, Resultados, Calverton, MD, USA: Macro International, 2000

17. Pallitto CC and O'Campo P, Community level effects of gender inequality on intimate partner violence and unintended pregnancy in Colombia: testing the feminist perspective, Social Science \& Medicine, forthcoming.

18. Ibid

19. Yllo K, Sexual equality and violence against wives in American states, Journal of Comparative Family Studies, 1983, 14(1):676-686; Smith MD Patriarchal ideology and wife beating: a test of a feminist hypothesis, Violence and Victims, 1990, 5(4):257-273; and Ellsberg M et al., Candies in hell: women's experience of violence in Nicaragua, Social Science $E$ Medicine, 2000, 51(11):1595-1610

20. Dyson T and Moore M, On kinship structure, female autonomy, and demographic behavior in India, Population and Development Review, 1983, 9(1):35-60; Govindasamy P and Malhotra A, Women's position and family planning in Egypt, Studies in Family Planning, 1996, 27(6) 328-340; and Hindin MJ, Women's autonomy, women's status and fertility-related behavior in Zimbabwe, Population Research and Policy Review, 2000, 19(3):255-282

21. Campbell JC, Sanctions and sanctuary: wife battering within cultural contexts, in: Counts DA, Brown JK and Campbell JC, eds., To Have and to Hit: Anthropological Perspectives on Wife Beating, Urbana, IL, USA: University of Illinois Press, 1999; Koenig M et al., Women's status and domestic violence in rural Bangladesh: individual- and communitylevel effects, Demography, 2003, 40(2):269-288; and Schuler SR et al. Credit programs, patriarchy and men's violence against women in rural Bangladesh, Social Science E Medicine, 1996, 43(12):1729-1742.

22. World Health Organization (WHO), Putting Women First: Ethical and Safety Recommendations for Research on Domestic Violence Against Women, Geneva: WHO, 2001.

23. Ellsberg $\mathrm{M}$ et al., Researching domestic violence against women: methodological and ethical considerations, Studies in Family Planning, 2001, 32(1):1-16.

24. Bankole A and Westoff CF, The consistency and validity of reproductive attitudes: evidence from Morocco, Journal of Biosocial Science,
1998, 30(4):439-455; and Moos MK et al., Pregnant women's perspectives on intendedness of pregnancy, Women's Health Issues, 1997, $7(6): 385-392$.

25. Helton AS, McFarlane J and Anderson ET, Battered and pregnant: a prevalence study, American Journal of Public Health, 1987, 77(10):13371339; and Stewart DE and Cecutti A, 1993, op. cit. (see reference 11).

26. Saltzman LE et al., Physical abuse around the time of pregnancy: an examination of prevalence and risk factors in 16 states, Maternal and Child Health Journal, 2003, 7(1):31-43.

27. Castro R, Peek-Asa C and Ruiz A, Violence against women in Mexico: a study of abuse before and during pregnancy, American Journal of Public Health, 2003, 93(7):1110-1116.

28. Ellsberg M et al., 2000, op. cit. (see reference 19).

29. Center for Reproductive Law and Policy (CRLP), Women's Reproductive Rights in Colombia-A Shadow Report, Washington, DC: CRLP, 1998.

30. Henshaw SK, Singh S and Haas T, The incidence of abortion worldwide, International Family Planning Perspectives, 1999, 25(Suppl.):S30S38; and Singh S and Wulf D, Estimated levels of induced abortion in six Latin American countries, International Family Planning Perspectives, 1994, 20(1):4-13

31. Torres A and Forrest JD, Why do women have abortions? Family Planning Perspectives, 1988, 20(4):169-176.

32. Joyce TJ and Grossman M, Pregnancy wantedness and early initiation of prenatal care, Demography, 1990, 27(1):1-17; Marsiglio W and Mott FL, 1988, op. cit. (see reference 6); Sable MR et al., Differentiating the barriers to adequate prenatal care in Missouri, 1987-88, Public Health Reports, 1990, 105(6):549-555; Morris NM, Udry JR and Chase CL, Reduction of low birth weight birth rates by the prevention of unwanted pregnancies, American Journal of Public Health, 1973, 63(11):935-938; Korenman S, Kaestner R and Joyce T, Consequences for infants of parental disagreement in pregnancy intention, Perspectives on Sexual and Reproductive Health, 2002, 34(4):198-205; Laukaran VH and van den Berg BJ, The relationship of maternal attitude to pregnancy outcomes and obstetric complications: a cohort study of unwanted pregnancy, American Journal of Obstetrics and Gynecology, 1980, 136(3):374379; and Bustan MN and Coker AL, 1994, op. cit. (see reference 6).

33. Gage AJ, Premarital childbearing, unwanted fertility and maternity care in Kenya and Namibia, Population Studies, 1998, 52(1):21-34; Chinebuah B and Perez-Escamilla R, Unplanned pregnancies are associated with less likelihood of prolonged breast-feeding among primiparous women in Ghana, Journal of Nutrition, 2001, 131(4):1247-1249; Dye TD et al., Unintended pregnancy and breastfeeding behavior, American Journal of Public Health, 1997, 87(10):1709-1711; and PerezEscamilla R et al., Specifying the antecedents of breast-feeding duration in Peru through a structural equation model, Public Health Nutrition, 1999, 2(4):461-467.

34. Baker J and Khasiani S, Induced abortion in Kenya, case histories, Studies in Family Planning, 1992, 23(1):34-44; Unuigbe JA et al., Abortion-related morbidity and mortality in Benin City, Nigeria: 1973-1985, International Journal of Gynaecology and Obstetrics, 1988 26(3):435-439; and Okonofua FE et al., Assessing the prevalence and determinants of unwanted pregnancy and induced abortion in Nigeria, Studies in Family Planning, 1999, 30(1):67-77.

35. CRLP, 1998, op. cit. (see reference 29).

\section{RESUMEN}

Contexto: La violencia contra la pareja intima está estrechamente relacionada con una serie de problemas de salud reproductiva y mental. Sin embargo, la relación entre la violencia intrafamiliar y la capacidad de la mujer para controlar su fecundidad no ha sido adecuadamente analizada, especialmente en los países en desarrollo.

Métodos: Se realizaron análisis de regresión logística multivariada con los datos recogidos en la Encuesta Nacional de Demografía y Salud de Colombia, del año 2000, con el objeto 
de estudiar la relación entre el sexo forzado y el embarazo no planeado, lo cual fue incluido como un indicador del grado del control que tenían las mujeres sobre su fecundidad. Asimismo, se estudiaron las diferencias regionales con respecto a esta relación y se calculó el riesgo atribuible poblacional. La muestra consistió en 3.431 mujeres casadas alguna vez, de entre 15 y 49 años, que hubieran dado a luz durante los últimos cinco años o que en ese momento estuvieran embarazadas.

Resultados: El 55\% de las entrevistadas habían tenido por lo menos un embarazo no planeado, y el 38\% habían sido física o sexualmente abusadas por su pareja actual o más reciente. La razón de momios ajustada entre las mujeres que habian tenido un embarazo no planeado fue significativamente más alta si habían sido abusadas física o sexualmente (razón de momios, 1,4); esta relación se observó en las regiones Atlántica y Central de Colombia (1,7 cada una), pero no fue significativa en otras regiones del país. Si se elimina la violencia contra la pareja intima en Colombia se calcula que podrían evitar unos 32.523-44.986 embarazos no planeados por año.

Conclusiones: Estos resultados señalan la necesidad de incluir la detección y el tratamiento de la violencia contra la pareja intima en los programas de salud reproductiva, de fomentar la participación del hombre en los programas de control de la fecundidad, y de mejorar la respuesta social y política ante la violencia contra la pareja intima.

\section{RÉSUMÉ}

Contexte: La violence par un partenaire intime est associée à plusieurs problèmes de santé reproductive et mentale. Le rapport entre cette violence et l'aptitude des femmes à maîtriser leur fécondité n'a toutefois guère été examiné, surtout dans les pays en développement.
Méthodes: Les données de l'Enquête démographique et de santé 2000 de la Colombie ont servi à l'étude, par régressions logistiques multivariées, du rapport entre la violence par un partenaire intime et la grossesse non planifiée, utilisée comme mesure de contrôle de la fécondité. Les différences régionales de ce rapport ont également été examinées, et la fraction étiologique du risque a été estimée. L'échantillon comptait 3.431 femmes mariées ou l'ayant jamais été, âgées de 15 à 49 ans et qui avaient accouché durant les cinq dernières années ou qui étaient enceintes.

Résultats: Cinquante-cinq pour cent des répondantes avaient eu au moins une grossesse non planifiée et 38\% avaient subi les violences physiques ou sexuelles de leur partenaire actuel ou de leur dernier partenaire. La probabilité corrigée pour les femmes d'avoir eu une grossesse non planifiée était significativement supérieure si elles avaient été victimes de violences physiques ou sexuelles (rapport de probabilités, 1,4). Observée dans les régions atlantique et centrale (1,7 chacune), l'association ne s'est pas révélée significative dans le reste du pays. L'élimination de la violence par un partenaire intime en Colombie donnerait lieu à une réduction annuelle des grossesses non planifiées estimée entre 32.523 et 44.986.

Conclusions: Ces observations révèlent la nécessité d'inclure le dépistage et le traitement de la violence par un partenaire intime dans les programmes de santé reproductive, d'encourager la participation des hommes aux programmes de contrôle de la fécondité et d'améliorer la réponse sociopolitique à la violence par un partenaire intime.

\section{Acknowledgments}

The authors thank Jacquelyn Campbell, Michael McQuestion and Andrea Gielen for comments on an earlier version of this article.

Author contact: cpallitt@jhsph.edu 